\section{Violência e saúde: contribuições teóricas, metodológicas e éticas de estudos da violência contra a mulher}

\author{
Violence and health: theoretical, methodological, \\ and ethical contributions from studies on \\ violence against women
}

\author{
1 Faculdade de Medicina, \\ Universidade de São Paulo, \\ São Paulo, Brasil. \\ 2 Departamento de Ciências \\ da Saúde, Universidade \\ Federal de São Paulo, \\ São Paulo, Brasil. \\ Correspondência \\ L. B. Schraiber \\ Departamento de Medicina \\ Preventiva, Faculdade de \\ Medicina, Universidade \\ de São Paulo. \\ Av. Dr. Arnaldo 455, 2 o andar, \\ sala 2245, São Paulo, SP \\ 01246-903, Brasil. \\ liliabli@usp.br
}

\begin{abstract}
This article discusses theoretical, methodological, and ethical aspects pertaining to violence against women as both a form of gender violence and a public health issue. The text provides epistemological reflections based on daily research experience with qualitative and quantitative, population-based, and service-user studies that address both women and men. Violence is defined as a complex and sensitive theme of a medical and social nature in terms of its theoretical-methodological approach, pointing to interdisciplinarity as the reference for its construction as an object of health. The article discusses the difficulties in linking the various sciences, methodologies, and theoretical perspectives. It also highlights the special dynamic between visible and invisible violence, with implications for research design, particularly for demarcating the object of study, a relevant issue given the technological needs of health intervention. These specificities of violence raise further ethical issues for the production of knowledge, and there is a need for special care as part of methodological quality in the research. Research ethics is also responsible for the scientificity of the resulting data. Situations stemming from specific studies are used to illustrate the article's commentary.
\end{abstract}

Violence Against Women; Gender and Health; Research Ethics
Lilia Blima Schraiber 1

Ana Flávia Pires Lucas d' Oliveira 1

Márcia Thereza Couto 2

\section{Campos científicos, pesquisas e objetos - interfaces}

Neste texto refletimos acerca das dimensões teórica, metodológica e ética em estudos que tomam a violência contra mulheres como objeto da Saúde Coletiva, pretendendo mostrar suas necessárias imbricações. Referidas à saúde, nossas considerações estão, ainda, circunscritas à violência nas relações interpessoais de gênero. Também examinaremos as interfaces daquelas dimensões; não cada qual. Por fim, trata-se de elaborações feitas com base em cotidianos de pesquisa; reflexões epistemológicas de cientistas acerca de suas práticas.

Produção similar não é novidade nas Ciências Humanas e Sociais, ainda que incomum em outros campos e também na Saúde, quer em seu ramo experimental biomédico, quer na Epidemiologia. Em estudos do social, são as pesquisas qualitativas, pela característica da experiência de campo da qual se investe o pesquisador, as que fomentam inúmeras discussões de natureza teórico-metodológica e ética no fazer da pesquisa. No entanto, encontraremos alguns textos que tratam também das pesquisas sociológicas quantitativas. Inspiram-nos, portanto, Bourdieu et al. 1, ou o clássico livro organizado por Nunes 2 , com os magistrais textos de DaMatta (O Ofício de Etnólogo, ou Como Ter “Anthropological Blues”, 1978) e de Velho (Observando o Familiar, 1987). É com a qualidade de "lições aprendidas no dia- 
a-dia" que pretendemos contribuir ao nosso campo.

Consideremos, primeiramente, que para a produção do conhecimento científico há duas modalidades de relações necessárias: entre referenciais teóricos e metodológicos; e entre metodologia e ética da pesquisa. A primeira dessas relações indica que as escolhas de recortes do objeto e sua problematização em hipóteses ou teses implicam restrições correlatas de ordem metodológica, definindo certo leque de possíveis métodos 3,4. Essa conexão necessária, tratada em diversas publicações, diz respeito à definição filosófico-política do conhecimento que se quer produzir e como concretizá-la no processo investigativo 5,6. As relações entre metodologia e ética da pesquisa, por sua vez, sobretudo relativamente à produção dos dados empíricos, implicam especiais cuidados no trabalho de campo. Estes caracterizam a responsabilidade ético-social do pesquisador, tema que ainda merece maior exploração.

Em segundo lugar, em pesquisas do social, essas reflexões dos cientistas sobre suas práticas são, em boa medida, porém não exclusivamente, necessidade da modalidade qualitativa de pesquisa. A interação entre sujeitos e objetos da pesquisa, que marca as temáticas do social e encontra-se exaltada na abordagem qualitativa 7 , exige, para uma objetivação do problema em estudo, uma constante publicação do processo investigativo. São esclarecimentos das decisões e posicionamentos por parte do pesquisador, tanto teórico-científicos quanto filosófico-epistemológicos e que garantem a confiabilidade do conhecimento produzido.

Tais esclarecimentos não são suficientes apenas até a etapa do trabalho de campo, substantivamente representada pelo término da definição das técnicas de coleta de dados. Interromper aí a publicização de decisões e posicionamentos representa uma leitura superficial das necessidades epistemológicas da produção de conhecimento científico. Fazem-no, contudo, aqueles que crêem ser ocioso tecer esclarecimentos para além da definição metodológica inicial. Essa percepção está dada pelo referencial positivista. Para o positivismo, a garantia da objetividade dá-se com base em uma neutralidade que busca suspender a interação sujeito-objeto na produção do empírico, restringindo as escolhas do pesquisador até aquele momento e, em menor medida, quando busca interpretar os "achados". Isto termina por sugerir que o trabalho de campo seja mais "coleta” do que produção de dados.

Todavia, se mesmo para esse referencial seria importante explicitar todas as tomadas de decisão ao longo do estudo, para outros é imperioso, como ocorre em grande parte dos objetos das Ciências Humanas e Sociais. Voltadas para apreender o humano na dinâmica social (atitudes, comportamentos) ou para apreender objetos tão ativos quanto o pensamento, tal qual nos estudos sobre subjetividades (percepções, representações, opiniões, juízos de valor ou crenças), essas ciências requerem freqüentemente métodos e técnicas igualmente dinâmicos: a modalidade qualitativa de pesquisa. Nesta, a produção de dados tem sempre lados "em aberto", tendo como grande vantagem epistemológica exatamente a flexibilidade na apreensão dos objetos 8 , base da necessária apresentação de escolhas e percursos realizados.

Além disso, os esclarecimentos do pesquisador são rigorosamente necessários até o final de seu estudo, alcançando também escolhas interpretativas do empírico, o que se costuma chamar na pesquisa qualitativa de "análise" dos dados, muito longe, porém, do significado desse mesmo termo para as abordagens quantitativas.

Assim, em especial na modalidade qualitativa, tornar pública a posição que o pesquisador assume, desde a construção de seu objeto de conhecimento ao conhecimento produzido, com o término da análise e discussão dos dados, é o controle (e a garantia, por intermédio da transparência) de que a objetivação foi realizada, mesmo sem a neutralização da presença do pesquisador na investigação. Quem avalia e atesta a cientificidade, sendo nisto a pesquisa qualitativa exatamente igual à quantitativa, é a comunidade científica implicada ${ }^{9}$, guardadas, claro, as especificidades normativas de cada qual.

Mas se na pesquisa qualitativa, a comunidade científica requer detalhados esclarecimento acerca dos pressupostos e procedimentos da investigação, nas pesquisas quantitativas, tais informações estão pressupostas nos instrumentos de produção de dados: um bom (consistente) questionário, por exemplo, traz em si as variáveis relevantes e necessárias ao objeto em foco, já dialogando com a comunidade científica respectiva (daí as revisões de literatura) e já formuladas de modo a serem compatíveis com as análises (estatísticas) futuras: trata-se de elaboração conectada às perspectivas teóricas e metodológicas adotadas. A aplicação de um instrumento que é "fechado" deixou o pesquisador e suas escolhas para fora do processo de produção dos dados nesse momento da investigação empírica. Quanto mais o faz, ou seja, quanto mais pré-delimitado o instrumento parecerá melhor a cientificidade do estudo. Sabemos, entretanto, assim como o mostram críticos do positivismo, que o pesquisador em seu cotidiano termina por fazer diversas escolhas de percurso, nem sempre reveladas. 
De outro lado, o modo de informar as respectivas comunidades científicas é diverso para as várias Ciências e, em cada qual, para os direcionamentos mais teóricos ou mais empíricos de seus estudos, ou para as modalidades qualitativas e quantitativas de pesquisa que adotam. As diferentes Ciências possuem, de fato, formas diversas de cumprir as exigências da produção de conhecimento: constroem os objetos, realizam a investigação empírica, analisam seus dados e apresentam seus estudos de modo distinto entre si. Afinal, constituem linguagens e formas de comunicação também específicas.

Ocorre que a experiência de pesquisa de que ora tratamos (violência de gênero como agravo à saúde) colocou-nos entre fogos cruzados. Um deles foi a combinação das abordagens qualitativa e quantitativa, que adotamos tanto pela pouca exploração desse objeto, quanto pela articulação pretendida entre domínios de conhecimentos diversos: aqueles sobre a ocorrência e distribuição de práticas de violência, dos significados da experiência de violência para os sujeitos envolvidos nessas situações e da relação entre violência e os danos à saúde (doenças e seus riscos). Isto nos levou a lidar com tradições científicas diversas.

Não se trata, no entanto, somente de distinguir pesquisas qualitativas das quantitativas, questão que se coloca também para o interior das próprias ciências do social. Independentemente de qual dessas modalidades seja desenvolvida, na produção científica em Medicina e em Saúde Pública agrega-se uma especificidade adicional: trata-se do aspecto "intervenção". Introduz-se, assim, a questão tecnológica para a definição dos objetos científicos nesses campos.

Adicionalmente, ao focarmos nossos estudos na abordagem da violência como questão de gênero, enfrentamos outro fogo cruzado, para além das complexas relações entre os interesses da pesquisa científica e os das intervenções técnicas. A aproximação de gênero da violência contra a mulher remete às relações íntimas das parcerias afetivo-sexuais 9,10,11 e tem nas relações sexuais forçadas um segundo traço distintivo 12,13,14. Logo, nosso objeto agrega outras especificidades para sua objetivação. Ligadas às emoções e às intimidades que tal violência envolve, essas especificidades demandarão cuidados metodológicos especiais: de natureza ética.

É do conjunto dessas considerações que afirmamos, enquanto teses acerca da violência de gênero contra a mulher, ser este tema complexo quanto ao empreendimento teórico-metodológico, caracterizando na saúde um objeto de natureza interdisciplinar, a que denominamos objeto médico-social; e tema sensível e, nisto, objeto fu- gidio ou instável quanto à sua delimitação para a produção do dado empírico.

A seguir exploraremos cada uma, ainda que ambas sejam qualificações integradas e não meramente justapostas nesse objeto. Trata-se, contudo, da perspectiva analítica para se chegar à síntese final, em que o exame de cada esfera busca ressaltar sua articulação com a outra, como é da tradição da dialética 6 .

\section{Da complexidade: interdisciplinaridade e o diálogo entre o teórico e o empírico}

É amplamente reconhecido o fato de que a violência é estabelecida como objeto primeiro nas ciências humanas e sociais e na filosofia, relativamente à saúde. Essa precedência é particularmente relevante no caso da violência contra a mulher, que surge na saúde a partir de 1995.

Esse fato, além da violência ter sido objeto de intervenção também primeiro nos setores da segurança pública e do sistema judiciário, facultou aos profissionais da saúde o entendimento de que sua atuação poderia restringir-se às conseqüências físicas ou mentais da violência, restando ela mesma como um problema daqueles outros campos, o que é mencionado no relatório mundial sobre violência e saúde 15 .

No entanto, aqui se defende a relevância de se intervir nos termos da saúde, compondo esforços e trocas com outros setores sociais e campos científicos, seja na recuperação das vítimas, seja, sobretudo, prevenindo novos danos. Com isso a violência deve ser instituída como objeto de conhecimento e intervenção também do campo da Saúde, reafirmando a proposição da Organização Mundial da Saúde (OMS) nesse sentido 15.

De outro lado, ao tomarmos a violência contra a mulher como questão de saúde e de Saúde Pública, não apenas já contamos com uma rica produção de explicações no âmbito das ciências sociais e da filosofia, como passamos a nos defrontar com as mencionadas composições de conhecimentos e de modos de pesquisar. Construir, portanto, a violência como objeto pertinente à saúde implica um grande desafio.

Primeiro, a questão da interdisciplinaridade, um dos significados que estamos atribuindo à qualificação de 'complexo' para nosso tema. Reconhecemos, então, a insuficiência de disciplinas isoladas para conhecer a violência, além das incertezas, contradições e pluralidade que caracterizam este objeto 16,17. Conhecê-lo talvez se situe mais na ordem do possível do que do previsível.

Segundo, há o desafio de articularmos conhecimentos produzidos sob diferentes finalidades 
sociais. Chamamos a atenção para as vocações com que as diferentes regiões do conhecimento foram sendo construídas como ciência moderna: algumas mais voltadas que outras para uma imediata intervenção social. Aderindo a um maior pragmatismo enquanto seu particular propósito, algumas ciências detêm um caráter aplicado (tecnológico) maior ou mais imediato, dentro do movimento histórico de instituição das áreas de conhecimento e como parte da construção da razão instrumental que se dá desde o Renascimento quanto ao sentido social do conhecer 18,19 .

A saúde, desde a modernidade a princípio estruturada em torno da recuperação de doentes e controle de epidemias, é um dos mais tecnológicos campos científicos 19 . Não porque disponha de muitos equipamentos, mas porque orientou para tal direção seu conhecimento e seu modelo de ciência. Vale dizer, o que é notório nas ciências da medicina, trata-se de produção de conhecimento voltada para criar muitas tecnologias. Pode-se observar este aspecto pela historicamente bem sucedida eficácia de suas práticas médica e sanitária, em termos das respectivas intervenções. Esta eficácia que, lembremos, é também de natureza técnica, resulta da redução de seus objetos ao biológico, redução que suas ciências operaram naturalizando o social.

Para pertencer à saúde e partilhar dessa competência na intervenção, é mister construir a violência como objeto de conhecimento técnico-científico. Mesmo que se recuse igual naturalização dos objetos sócio-culturais 20 , ainda assim resta a exigência de ser conhecimento tecnológico: conhecimento capaz de gerar em curto prazo procedimentos de assistência individual e de saúde pública, com programas de prevenção e promoção da saúde.

Ademais, isto significa também demonstrar a violência como questão tão importante a ponto de gerar políticas públicas para a intervenção, para o que se requer conhecer a violência na expressão de sua magnitude social, em seus grandes números e certas regularidades de ocorrência populacional, o que representa a convergência dos propósitos da Saúde Pública com as raízes históricas da produção do conhecimento em violência, em especial a violência contra a mulher, introduzida como questão pelo movimento social feminista 21,22,23.

Esse caráter tecnológico do campo não obriga à redução biomédica, como se fosse exigido ignorar os conhecimentos da violência como fato humano sócio-cultural. Passa a ser nosso desafio, então, fazer alguma redução tecnológica sem que se opere uma ruptura entre as compreensões da violência de ordem filosófica ou sócio-antropológica e as de ordem médico-sanitária, evitando considerar o primeiro conjunto de conhecimento muito interessante mas externo à explicação propriamente médica ou de saúde. Esse corte apenas nos remeteria novamente a uma abordagem só dos efeitos da violência no corpo dos indivíduos.

Uma redução tecnológica demanda formulação do objeto de estudo, desde o início, própria às futuras intervenções. Trata-se de domínios da realidade bem delimitados, em que a pesquisa não pode se ater às elaborações mais genéricas e abstratas, devendo, o máximo possível, alcançar âmbitos concretos e particulares da realidade. Porém, sem perder a riqueza de teoria - as qualificações humanas, sociais e culturais de violência, o que é, repetimos, construído no diálogo empírico-teórico. Afinal, o conhecimento é o concreto pensado 5,6 .

A passagem e interações recíprocas entre o teórico, o empírico e o tecnológico, portanto, são, a nosso ver, o grande embate dos objetos imediatamente sócio-culturais e médico-sanitários. Vamos denominá-los de "objetos médico-sociais", em resgate histórico de um dos saberes fundadores da Saúde Coletiva: a Medicina Social 24. Ademais esse não é um desafio apenas da violência como questão de saúde, uma vez que, por aproximação, entendemos que há outros objetos tão complexos e sensíveis quanto este: drogadição, sexualidade e loucura, por exemplo, são também problemas médicos e sanitários de peculiar constituição quanto às relações entre o biológico e o sócio-cultural. Produzem, a nosso ver, questões similares para o campo da saúde.

A seguir vamos considerar esse desafio, discutindo as relações entre as contribuições teóricas que adotamos, já enquanto uma dada combinação interdisciplinar, e as bases empíricas em desenhos concretos de investigações. A composição de referências teórico-conceitual, representativa de uma pretendida conversa interdisciplinar, mereceria uma reflexão em si. Não sendo possível fazê-la no âmbito deste artigo, apresentaremos seu quadro final e já aplicado ao nosso objeto, a violência de gênero como agravo à saúde - objeto construído e interpretado por meio de suas referências.

Como base teórica, tomamos estudos filosóficos e sócio-culturais que elaboram a violência quer como questão social e humana mais geral, quer como questão das relações interpessoais em particular, além daqueles que a tratam como questão de gênero. Também tomamos estudos epidemiológicos que caracterizam tipos e expressões das violências e aspectos sócio-culturais relacionados - quer como contextos ou fatores associados, quer como possíveis causas ou efeitos da violência na saúde, em sociedades 
culturalmente diversas. Resgatamos, por conseguinte, um amplo leque de contribuições. As considerações que seguem, porém, são, ainda, primeiras delimitações, não pretendendo um quadro acabado.

Qualificamos violência como realidade sóciocultural e não biológico-natural. Distinguiremos conceitualmente, com Minayo \& Souza 25, "violência” de "agressividade humana”, diferenciando "impulso natural" de "gesto cultural", porque enquanto a agressividade associa-se a necessidades de sobrevivência, a violência é fenômeno criado na vida em sociedade: ato de intenção socialmente construída.

Também a tomamos como questão de gênero 9,26,27, sendo Gênero um conjunto de referências que estrutura a organização material e simbólica de toda a vida social. Conseqüentemente, uma construção histórica que estrutura a percepção e produz atitudes e comportamentos. Ocorre que essas referências baseiam-se nas diferenças entre os sexos, em termos de seus estatutos sociais. Representam diferenças de poder e, então, desigualdades de valor social 28 . Sexo será, pois, uma distinção de ordem biológica entre homens e mulheres, traços de distinção entre corpos de indivíduos (masculinos e femininos) e como tal será uma categoria do empírico (ou uma variável na abordagem quantitativa). Gênero, por sua vez, designa as relações sociais e culturais entre homens e mulheres, ou entre as mulheres, ou, ainda, entre os homens, não enquanto apenas indivíduos deste ou daquele sexo, mas enquanto sujeitos sociais dotados de identidades e atribuições em razão de suas relações. A elaboração que se dá em torno a gênero será, portanto, uma construção conceitual da dimensão relacional no exercício das feminilidades/masculinidades, apontando sempre para a desigualdade de poder historicamente dada, com o domínio do masculino. Este processo recobre o corpo biológico em seus usos historicamente construídos 20 , sendo, então, gênero uma categoria analítica e como tal formuladora de conceituações teóricas, em estudos qualitativos ou quantitativos.

Ao tomarmos a violência contra a mulher como questão de gênero, temos por hipótese que as relações entre homens e mulheres encontram-se sob conflito e as formas interativas em crise, isto é, sob ameaça de ruptura da dominação tradicional. Aviolência surge como comportamento de reconquista do poder ou para prevenir sua perda 29,30. No último caso, a violência poderá ser tida como uma prática educativa, de aculturação nas tradições, tal qual, tempos atrás, foi concebida na educação de crianças. É claro que no caso das mulheres adultas, trata-se de sua infantilização como sujeitos sociais: as mulheres seriam inca- pazes de exercício responsável (autônomo) de subjetividade.

Que não estranhe tanto, pois, o fato de que os homens mais tradicionais, quando agressores de suas parceiras, não apresentem qualquer constrangimento moral em sê-lo. Isto foi relatado em nossas pesquisas com homens, ao oposto do que esperávamos com base em nossos valores de pesquisadoras, mulheres de alta escolaridade e aderidas aos direitos humanos e das mulheres. Efetivamente, alguns desses homens acreditam que corrigem o desvio de uma ordem que acham correta ou crêem que contribuem para uma boa educação dos comportamentos. Outros apenas valorizam o próprio poder e entendem que isso seja absolutamente correto (ético). Essas representações emergiram quando homens foram solicitados a informar agressões contra suas parceiras em pesquisas que realizamos quer na modalidade qualitativa, com a técnica de grupos focais 13 , quer na modalidade quantitativa, com a aplicação de questionários fechados a grandes amostras 31. Os grupos focais masculinos, diferenciados sócio-demograficamente entre si, foram desenvolvidos dentro do estudo multipaíses que, por inquérito domiciliar, pesquisou a violência contra a mulher no Município de São Paulo e em 15 municípios da Zona da Mata de Pernambuco 11. Em conjunto com grupos focais femininos (de mesma distribuição) e entrevistas com mulheres e profissionais de serviços, representaram uma etapa qualitativa para pesquisar a violência de gênero e também apoiar a construção do questionário domiciliar 11,32. Diferenciados segundo estrato social e residência urbanorural, os grupos permitiram-nos caracterizar as representações dos homens acima denominados "mais tradicionais" quanto às relações de gênero.

Que também não se estranhem, de outro lado, as dificuldades morais, emocionais e materiais que as mulheres têm para lidar com e falar sobre a violência 33,34 . As mulheres relatam sentir: vergonha ou humilhação; culpa ou medo de serem culpadas pela violência; temor pela sua segurança e a de seus filhos; falta de controle sobre suas vidas; esperança de que o agressor mude, dado que ele promete; medo de perder os filhos; vontade de proteger o parceiro por razões econômicas ou afetivas.

Afinal, concordando com Habermas 35 (p. 115), há os bloqueios da ideologia que interceptam os processos comunicativos, formando “...convicções graças às quais os sujeitos se iludem sobre si mesmos e sobre a sua situação". E transformando violência em poder, as ideologias tornam plausíveis “... sistemas de dominação que excluem, de fato, a formação discursiva da vonta$d e " 36$ (p. 25). 
Da perspectiva empírica, como aponta Heise ${ }^{30}$, os contextos em que essa violência de gênero mostra-se como aceitável são aqueles em que existem: normas culturais ou legais dando direitos de propriedade masculina sobre as mulheres; controle exclusivo masculino sobre a riqueza e bens da família; e noção de masculinidade como soberania dos homens sobre as decisões da vida conjugal e em família, além de maior liberdade e poder para definir comportamentos adequados, por exemplo, o exercício da sexualidade das mulheres e outros comportamentos ligados à honra da família, dignidade masculina.

Da perspectiva teórica, nas relações que estabelecem os sujeitos com a normatividade social, e que se dão mediante as relações intersubjetivas, a violência será uma ausência de poder, como propõe Arendt 37 (p. 36): "O poder corresponde à habilidade humana não apenas para agir, mas para agir em concerto. Violência... distingue-se por seu caráter instrumental. ...nas relações internacionais tanto quanto nos assuntos domésticos, a violência aparece como último recurso para conservar intacta a estrutura de poder contra contestadores... de fato é como se a violência fosse o pré-requisito do poder... mais de perto, entretanto, esta noção perde muito de sua plausibilidade".

Trata-se de assumirmos a essência do poder como a possibilidade da interação, distinguindo este exercício de seu uso instrumental 38. Neste, a autoridade que se instala não se encontra legitimada, mas imposta (pela força física ou temor desta). Como aponta Foucault 39 (p. 243 ): “Uma relação de violência age sobre um corpo, sobre as coisas; ela força, ela submete, ela quebra, ela destrói, ela fecha todas as possibilidades... Uma relação de poder, ao contrário, se articula sobre dois elementos que lhe são indispensáveis por ser exatamente uma relação de poder: que o 'outro' (aquele sobre o qual ela se exerce) seja inteiramente reconhecido e mantido até o fim como o sujeito da ação; e que se abra, diante da relação de poder, todo um campo de respostas, reações, efeitos, invenções possíveis".

Nessa distinção entre violência e poder podemos ir mais além, afirmando da perspectiva do humanismo emancipatório 40,41 , e criticando a visão mais estrita do empoderamento individual, que poder é um agir responsável, em que a interação se dá como uma abertura ao Outro, dentro de uma ética de interesse (cuidado) para com este Outro.

Nestas conceituações, a violência é a negação do propriamente humano (ser sujeito), daí que não se caracterize só como uma violação de direitos humanos, incluindo a dos reprodutivos e sexuais para as mulheres 22 , na perspectiva jurídico-legal. Mas que se caracterize também, do ponto de vista ético, como anulação da dignidade, impedindo o sentimento de esperança.

Não terá, então, apenas o significado de mais um agravo à saúde a associação verificada (e de grande força estatística) entre sofrer violência e apresentar ideação ou tentativas de suicídio, além de outros sofrimentos e transtornos mentais 10,42. Tem-se aqui uma radical autodesqualificação, trabalhada na literatura como baixa auto-estima. Mais que isso é, a nosso ver, a perda identitária de sujeito, que se, de início, representa a introjeção cultural do menor valor socialmente dado às mulheres, torna-se o substrato da dificuldade de contarem o acontecido a alguém, atingindo até mesmo a capacidade de nomearem os vividos 43,44 , tamanha a perda dos referenciais de linguagem, de lugar e sentido social de si e das possibilidades de interação.

Assim, embora a experiência de violência diga e ensine algo a seus participantes, e nesse sentido comunica-lhes algo, ela não constitui relação interativa entre esses sujeitos, mas uma ruptura da comunicação.

Relembremos, de um lado, que nosso recorte da violência está no plano interpessoal. De outro, que nossa definição de violência não se confunde com o simples exercício de poder, exercício de uma autoridade maior que foi, de algum modo, legitimada (aculturada). Esse exercício dos poderes desiguais - e que historicamente podemos contestar e, então, recusar - resulta no máximo em vivência do conflito nessas relações interpessoais, quando a desigualdade está sendo questionada. Da nossa perspectiva, violência é a tentativa de retomar o poder de forma ilegítima, pela força em atos ou equivalentes simbólicos, exercidos por um sujeito contra o outro. Tal distinção entre situação de violência e da vivência da desigualdade de gênero, nos remeterá também à distinção entre relações de gênero e violência de gênero.

Assim sendo, mesmo nos contextos culturais em que a aceitação da violência a torna tão naturalizada e qualquer tentativa de argüir o maior poder masculino, resulta mais facilmente em violências, devemos distingui-las das dinâmicas de conflitos ainda negociáveis, em que os sujeitos envolvidos poderiam chegar a novos consensos relacionais, incluindo maior eqüidade nas relações. No estudo desses ou de qualquer outro contexto - e quer nas pesquisas qualitativas, quer nas quantitativas - teremos de diferenciar os comportamentos violentos daqueles que expressam exercícios de poderes por parte de seus sujeitos, ainda que desiguais. Por essa razão, em nossos estudos, operamos uma diferença entre comportamentos masculinos que podemos classificar como "controladores" - por exemplo, res- 
tringir contato da mulher com amigos ou família; querer saber onde ela está o tempo todo - relativamente a outros que consideramos violências, como discriminado em Schraiber et al. ${ }^{44}$, embora em muitas pesquisas não encontremos essa mesma diferenciação. Além disso, nossos grupos focais e entrevistas com mulheres mostram que certos comportamentos controladores como o ciúme, mesmo muito freqüente e sem situação definida para acontecer, ou um controle constante da parceira, podem ser compreendidos como atenção e cuidado. E embora associados estatisticamente com os atos de violência, não são culturalmente interpretados como a própria violência ou sequer como sua pré-condição. Tais representações das mulheres são, então, indicativas dos "bloqueios ideológicos" antes definidos.

Diante de todos esses aspectos até aqui considerados, já podemos antever a grande diversidade de recortes e planos de aproximação da realidade em desenhos concretos de pesquisa. No sentido de certa delimitação dessa área de estudos, assistimos à emergência de definições como a adotada pela OMS 15 que funcionam como noções operativas da pesquisa em violência na saúde. Definições que por vezes resultam insuficientes ou até imprecisas do ponto de vista conceitual, mas que oferecem referências preliminares. A qualidade operativa é dada pelo modo como são formuladas, visto que descrevem os concretos particulares vividos. Ao apresentarem explicitamente certos atos e danos, tais definições estabelecem comunicação mais fácil também junto às propostas de intervenções, deixando mais claro sobre quais situações se vai intervir e permitindo abordagens mais concretas também junto às mulheres nos serviços. No âmbito dos serviços, como se considera mais adiante, os tipos de expressão da violência ajudam a delinear qual a situação que será abordada pelos profissionais, pois isto implicará orientações diversas aos distintos casos.

Cumpre destacar que ao serem nomeadas como violências, tais situações serão dotadas daqueles significados da elaboração conceitual mais abstrata, tais como violação de direitos, coisificação dos sujeitos, anulação comunicativa e uso instrumental do poder.

Do ponto de vista empírico, essas noções operativas ainda parecem muito gerais. De um lado, em razão da polissemia do termo violência. Por exemplo, no contexto de São Paulo, entre mulheres usuárias de serviço público de saúde 43, violência foi referida particularmente ao estupro por estranhos, ainda que em parte (menos de $50 \%$ das vezes) fosse mencionado por mulheres que também relataram agressões e abusos por parceiro íntimo. Nestas, a menção foi maior en- tre mulheres que haviam sofrido relações sexuais forçadas $(70,3 \%)$ do que as que relataram agressões físicas $(46,9 \%)$. Isto recomendaria usar na produção dos dados empíricos uma listagem de atos bastante completa e com boa discriminação terminológica entre eles.

De outro lado, a banalização de alguns comportamentos retira-os dos significados da violência. Por exemplo, em nossos grupos focais com indivíduos de baixa escolaridade 13, os atos violentos, se não sempre e imediatamente aceitáveis, encontram justificativa para os homens que os concebem como ação instintiva à provocação das mulheres - "ela me faz perder a cabeça"; é o depoimento. E neste caso, a ação decorrente seria corretiva do comportamento das mulheres. Para as mulheres, porém, embora majoritariamente sequer seja justificável, a violência é vista mais como comportamento trivial ou fatalidade do que uma exigência corretiva, ainda que em alguns casos também apareça a última percepção. Compreendemos as representações das mulheres como produto, de um lado, da ocorrência tão comum da violência. As altíssimas prevalências encontradas dão conta desse aspecto: $29 \%$ em São Paulo e $37 \%$ na Zona da Mata de Pernambuco, de violência física e/ou sexual alguma vez na vida por parceiros íntimos 14 e 45,4 \% para esse mesmo tipo de violência entre as usuárias de serviços públicos de saúde em São Paulo 45. De outro lado, há a aceitação cultural de que o homem pode "perder a cabeça". Esse depoimento das mulheres surge, via de regra, acompanhado de justificativas do comportamento masculino expressas por elas próprias: "não fez por mal" ou então "quando ele bebe" perde mesmo a cabeça. Entenda-se: em determinados contextos, o homem teria direito a perder o controle, seria moral e culturalmente permitido. E nesse sentido é tido como comportamento "natural", ou atenuado por circunstâncias tidas como inexoráveis, por exemplo, beber, também visto como comportamento "natural" para os homens.

Assim sendo e como forma de responder à específica necessidade, no caso da Saúde, de delimitar âmbitos de intervenção futura, existe um arrolamento desses atos e comportamentos (estapear, socar, surrar, chutar, obrigar a relação sexual, aterrorizar, intimidar etc.) ${ }^{14}$. Estes passam a representar as violências no plano dos protocolos de pesquisa e intervenção. Passam a ser as "expressões da violência", ou seus "tipos" (psicológica, física ou sexual) 14. Tal concretização da violência em indagações realizadas por meio da discriminação de atos e comportamentos delimitados e culturalmente bem claros tem sido recomendada tanto para pesquisas qualitativas como para as quantitativas. Nas quantitativas, 
surge como questão metodológica nuclear, até para que se produzam estudos comparáveis e de grande força ético-política na luta contra a naturalização e a banalização da violência, ao mostrarem as altíssimas magnitudes encontradas como fenômeno transcultural 11 .

Vamos abordar essa questão a seguir, refletindo acerca das dificuldades que a delicadeza do tema e a sensibilidade que evoca trazem para os estudos da violência de gênero, cuja marca distintiva, relembremos, está nas relações de intimidade e nos abusos ou agressões sexuais.

\section{Da sensibilidade: mútuas implicações entre ética e método}

As considerações anteriores já apontam para a sensibilidade do tema, ao mostrarem a violência como dramática vivência de negação do humano. Os sentimentos evocados, como medos, vergonha, humilhação, caracterizam a grande tensão emocional gerada na socialização desse vivido, movimento necessário para a produção dos dados. Também as referências ideológicas que banalizam, introjetando, a violência, assim como as de gênero que desqualificam o ponto de vista das mulheres, acrescentam compreensão acerca de outros mais sentimentos que as mulheres expressam como culpa e desesperança 13, potencializando todos eles a paralisia da fala.

Tais questões e o fato de que a experiência de cada qual acentua o singular nesses casos, tornam a visibilidade uma questão central: há uma especial dinâmica entre o visível e o invisível nesta violência de gênero. A apontada dificuldade em nomeá-la e a presença da dor crônica como sofrimento freqüentemente associado a essa experiência, levou-nos a considerar a violência como a dor que não tem nome 43 .

Além disso, sendo a pesquisa quantitativa desenhada como inquéritos por evento referido, ou no caso das qualitativas, como depoimentos sobre vividos, essas formas de investigação serão tanto produtos como produtoras daquilo que será ou não revelado por quem experimentou a violência. Portanto, também definem as dinâmicas de visibilidade.

A discussão entre visibilidade ou não-visibilidade é corrente na reflexão epistemológica que argúi o paradigma da objetividade tal como adotado pelo positivismo. Em nosso caso, a discussão, ainda que também se relacione à crítica paradigmática, situa-se, neste momento, no plano mais singelo e aplicado do trabalho de campo. Neste, quer em pesquisa qualitativa ou quantitativa, não há como ignorar a presença de semelhante sensibilização de que é tomado(a) o(a) pesquisador(a). Assim, a mobilização emocional que o tema violência acarreta ocorre de parte a parte - nos entrevistados e nos entrevistadores.

A princípio tomamos tal apontamento pela eventual identificação entre entrevistador-entrevistado em termos do humano-genérico. Contudo, diante das altas taxas de violência, percebemos que o(a) pesquisador(a) de campo tem grandes possibilidades ter vivido similar experiência ou ter estado muito próximo a alguém que a viveu. $O$ preparo desse(a) pesquisador(a), nesse sentido, torna-se parte da melhor forma metodológica de se contornar a dificuldade em ouvir e em perguntar. E como parte desses relatos pode indicar situações de risco de vida dos sujeitos pesquisados, não se pode eticamente desconhecer esse fato: há que se preparar a investigação de campo para tal, isto é, ser capaz de lidar com as situações de urgência e referir a serviços competentes. Logo, antes do início de trabalhos de campo, recomendamos o mapeamento de serviços que atendem mulheres ou homens em situação de violência para dispor de sua listagem, como comentaremos adiante.

A formação especial dos pesquisadores de campo vai além desse "saber referir", pois igualmente não se pode desconhecer o fato ético que representa toda e qualquer revelação de violência: há que preparar o(a) entrevistador(a) para acolher a qualquer delas, isto é, mesmo as que não impliquem imediato risco de vida, porque são sempre dramáticas revelações. Passa a ser uma questão, nesse sentido, acolher a quem relata e, ainda assim, manter a atitude investigativa enquanto produção de pesquisa científica, evitando que a situação, mesmo provendo um primeiro acolhimento, seja transformada em assistência a "casos diagnosticados".

Muitas vezes o(a) pesquisador(a) de campo sentir-se-á descobrindo casos: $23 \%$ das entrevistadas em seus domicílios, revelavam pela primeira vez a violência 32,44. Além disso, 82,6\% referiram-se satisfeitas pela oportunidade de falar 32 . Tal situação nos demonstra a relevância desses cuidados éticos. Agregue-se, ainda, a satisfação expressa por nossos pesquisadores de campo pela possibilidade de disseminarem durante a aplicação dos questionários informações sobre direitos humanos e suportes sócio-assistenciais. Por isso, além de um treinamento bastante detalhado para o trabalho de campo 46 , a pesquisa sempre contratou alguns serviços de atendimento para referir as situações cabíveis: as de risco de vida, necessariamente, mas também quando a(o) entrevistada(o) o solicitou. Isto foi feito sempre previamente ao trabalho de campo em nossos estudos populacionais ou com usuários de serviços (mulheres e homens), em São Paulo 
ou Pernambuco. Os serviços foram selecionados com base em mapeamento prévio de todos os existentes em cada local de estudo, o que nos permitiu publicar Guias de Serviços, para mulheres e homens, em rede intersetorial (saúde, jurídico, policial, orientações básicas e assistência psicossocial). Eles foram oferecidos a todos(as) participantes, caso quisessem tê-los para si ou para conhecidos(as). Neles foram registrados alguns dos direitos humanos e os direitos das mulheres, além de mensagens educativas e de apoio ético.

Cabe ainda considerar o sentimento de impotência de quem realiza escutas sobre violência, o que em situação de pesquisa, agrava-se pela incerteza quanto à continuidade do acolhimento. Há, ainda, sobretudo no caso das mulheres, o medo do agressor, compartilhado por quem escuta e quem relata. Este aspecto envolve questões de segurança pessoal, mais complicadas nas pesquisas domiciliares. Assim, tanto o sigilo da informação, quanto a privacidade do contexto da entrevista, são medidas éticas de confidencialidade dos dados e também, especialmente neste caso, precauções quanto à integridade física ou emocional dos participantes.

Esses cuidados protetores levaram-nos a estratégias especiais de campo, não só no inquérito populacional, mas também em serviços, das quais destacamos: a presença de psicólogas com a função de aconselhadoras para suporte psicoemocional das mulheres entrevistadas ou das entrevistadoras; o cuidado para que crianças maiores de dois anos não estivessem presentes à entrevista, entretendo-as com desenhos e fornecendo materiais a elas doados, como caixas de lápis coloridos e blocos de papéis. Adicionalmente, nunca entrevistamos a mulher na presença de outro adulto e um questionário-substituto foi usado caso qualquer pessoa ou o próprio agressor chegassem ao local da entrevista 32,33 .

Saliente-se que, de um lado, aconselhadores são componentes da equipe sempre indicados: nas investigações com mulheres e com homens. De outro, estes são procedimentos que geram maior confiança de entrevistadas(os) na pesquisa. Isto estabelece, em conjunto com o especial preparo das equipes de campo, vínculos apropriados na relação pesquisador(a) entrevistado(a), ampliando as condições de melhor revelação, elemento metodológico maior que vimos apontando neste texto.

A seguir consideramos duas outras questões muito relevantes para o trabalho de campo e o preparo de sua equipe, do ponto de vista do entrelaçamento ético-metodológico. Primeiro, como abordar o assunto da violência e manterem-se tanto os cuidados técnicos da aplicação de um questionário produtor de dados científi- cos, quanto os cuidados éticos da oferta de uma oportunidade de revelar-se algo muito delicado, realizando perguntas apropriadas. Neste sentido, a construção do instrumento é fundamental, assim como a capacitação quanto ao modo de conduzi-lo: o que e de que modo perguntar. Outra questão é como lidar com o referido sentimento de impotência que surge entre os membros da equipe de campo.

O sentimento de impotência importa porque, além de afetar moral e/ou emocionalmente a equipe - o que deve ser trabalhado nas supervisões de suas atividades - pode gerar estratégias, conscientes ou não, de recusa da pesquisa. Conseqüentemente, ocorrerá desestímulo aos relatos, na entrevista aberta ou na aplicação dos questionários, ou o desenvolvimento de sofrimentos pessoais de ordem emocional ou ética, por vezes levando a desistência do trabalho ou a agravos da própria saúde. Adiantemos que, conforme recomendações 34 , temos adotado a identidade de gênero, o que aplicamos nos estudos com mulheres (mulheres entrevistam mulheres) e com homens. Não de forma exclusiva, mas sobretudo com as mulheres, uma identidade maior também se verifica na concreta possibilidade da entrevistadora recordar situações pessoalmente experimentadas de violência, o que lhes agrava a realização da atividade. Instauramos, pois, como medidas protetoras nessa direção e para todas as pesquisas, a recepção diária das equipes ao final do período de trabalho, acolhendo seus relatos, de qualquer natureza, sobre a jornada vivida. Nesta ocasião, aconselhadoras foram sempre disponibilizadas, além de breves supervisões técnicas das entrevistas ou aplicação de questionário, o que se complementou com supervisões mais extensas, quase sempre semanais.

Por referência à abordagem apropriada, há recomendações da literatura 34,46 quanto a: duração adequada da entrevista e melhor localização das questões de violência em questionários, evitando-se ou os muito longos e cansativos, ou entrar subitamente em tema tão delicado; formulação das perguntas com clareza, facilitando o entendimento; exclusão de termos estigmatizantes (mulheres espancadas ou estupradas); enumeração dos atos; aumento das oportunidades de fala, perguntando as agressões físicas, sexuais e psicológicas, cada qual por sua vez, o que também representa definir distintos âmbitos ou domínios da violência de acordo com a própria plausibilidade teórica desse tema; capacitar a entrevistadora para a escuta e sua realização sem julgamento moral. Para este último, mas repercutindo nos demais, é fundamental a participação ou apoio de profissionais que lidam com esses casos ou já os pesquisaram. Conta- 
mos nesse sentido, para o estudo populacional e o realizado com mulheres usuárias, com consultores da saúde, das redes de atendimento a casos de violência, de grupos de pesquisa em Saúde e Ciências Sociais, juristas e advogados. Eles foram convidados, em São Paulo e em Recife, para constituírem comitês de acompanhamento da pesquisa, desde a etapa qualitativa e construção do questionário até os seminários finais, com público mais ampliado, de devolução e disseminação dos resultados. Também desde os primeiros estudos, contamos com parcerias oficiais de ONG feministas, nas duas cidades, além de outras que atuaram em conjunto nos treinamentos das equipes de campo.

Por fim, cabe considerar um último aspecto que, cremos, caberia para todos os temas complexos e sensíveis, além da violência de gênero. Trata-se do quanto se pode desenvolver, em uma mesma pesquisa, mais de um desses temas, ou abordá-los em pesquisa em que não são o tema central, tornando-o um produto apenas subjacente do estudo.

No já mencionado estudo multipaíses 11, surgiram diversas ponderações dessa natureza. Colocadas em termos da maior inibição dos relatos e maiores riscos quanto à segurança pessoal, disseram respeito ao entrecruzamento de duas condições estigmatizantes: sofrer violência, particularmente a sexual, e o pertencimento a determinadas etnias, em especial nos contextos de apartamento social formalmente instalado (em casos africanos e asiáticos). Retirou-se, assim, do questionário perguntas sobre a etnia das entrevistadas, evitando-se, em muitos países, o referido reforço negativo de se perguntar sobre a experiência de violência e também o pertencimento a tal ou qual agrupamento étnico ou prática religiosa, o que foi diferente no Brasil. Nós solicitamos especial permissão para incluirmos a variável cor da pele, a pedido do movimento de mulheres negras. Incluímos também prática religiosa, por acharmos a indagação relevante e factível em nosso país.

Outra questão foi o entrecruzamento das informações sobre sexualidade e matrimônio. Em diversos contextos, a simples pergunta sobre práticas sexuais prévias ao casamento formal constitui crime.
Essas situações representam contextos culturais específicos, o que, todavia, gera também debates acerca da delicadeza ética do tema violência, impedindo tomá-lo como um tema qualquer de pesquisa. Recomenda-se, assim, que se evite combiná-lo com outros temas, porque se torna ainda mais complicado garantir ética e metodologicamente procedimentos cuidadosos para todas as necessidades de exploração que então serão colocadas. Não tem sido consensual 33, por exemplo, a inclusão do tema violência em censos ou outros recenseamentos populacionais (como as Demographic Health Surveys).

Não se pode esquecer, porém, que a tradição cultural de cada país ou região, em termos de acolher pesquisas (sobretudo as domiciliares), falar com entrevistadores, revelar experiências pessoais de toda ordem, ou ainda trocar idéias e opiniões em geral, será sempre de grande repercussão na ética e na metodologia das pesquisas. Cabe notar o quanto, mesmo em São Paulo mas principalmente em Pernambuco, fomos sempre acolhidos, observando-se baixas recusas em abrir os domicílios (5\% e 1\%, respectivamente) ou dar a entrevista ( $4 \%$ e $1 \%$, respectivamente), em muito contrastando com outros países do estudo 11,32.

Mas se essa "cordialidade brasileira" facilita tais acessos, não faz superar as desigualdades, sejam as de gênero, étnicas ou sociais. Assim como não faz superar as repercussões ideológico-culturais derivadas e que marcaram toda esta nossa discussão acerca da produção do conhecimento em temas médico-sociais. Por isso, todos os cuidados éticos e metodológicos apontados foram, e acreditamos sempre serão, de grande benefício para a pesquisa também em nosso país.

Por fim e em síntese, cremos ser possível, com base em todas essas considerações, concluir que a face de objeto sensível e sensibilizador é aguçada pelo conjunto de questões que fazem da violência enquanto agravo à saúde um objeto também complexo. A complexidade potencializa sua qualidade sensibilizadora. Reciprocamente, a dinâmica da visibilidade articula-se com as questões de gênero, da interação sujeito-objeto e as objetivações buscadas pelo científico e pelo tecnológico. Por isso os procedimentos e cuidados que esta dinâmica motivou são, sem dúvida, igualmente recursos para lidarmos com a complexidade do objeto violência. 


\section{Resumo}

Tecem-se considerações teóricas, metodológicas e éticas acerca da violência contra a mulher como violência de gênero e objeto da Saúde Coletiva. São reflexões epistemológicas com base em cotidianos de pesquisas, com base em investigações qualitativas e quantitativas, populacional e com usuários de serviços de saúde, abordando-se mulheres e homens. Define-se a violência como tema complexo e sensivel, de qualidade médico-social quanto à sua tomada teóricometodológica, apontando-se a interdisciplinaridade como referencial para sua construção como objeto da saúde. Discutem-se as dificuldades na articulação de distintas ciências, metodologias e perspectivas teóricas. Aponta-se também a especial dinâmica entre o visível e o invisivel em violência, com implicações para os desenhos de pesquisa, em particular na delimitação do empírico, o que se torna uma relevante questão diante das necessidades tecnológicas da intervenção em Saúde. Essas especificidades da violência colocam ainda questões éticas particulares para a produção do conhecimento, havendo necessidade de cuidados especiais como parte da qualidade metodológica da pesquisa. A ética da pesquisa mostra-se igualmente responsável pela cientificidade dos dados produzidos. Situações das pesquisas realizadas ilustram as considerações desenvolvidas.

Violência Contra a Mulher; Gênero e Saúde; Ética em Pesquisa

\section{Referências}

1. Bourdieu P, Chamboredon JC, Passeron JC. A profissão de sociólogo: preliminares epistemológicas. Petrópolis: Editora Vozes; 1999.

2. Nunes EO, organizador. A aventura sociológica objetividade, paixão, improviso e método na pesquisa social. Rio de Janeiro: Jorge Zahar Editor; 1978.

3. Bruyne P, Heman J, Shoutheete M. Dinâmica da pesquisa em ciências sociais. 2a Ed. Rio de Janeiro: Editora Francisco Alves; 1977.

4. Samaja J. Epistemología y metodología: elementos para una teoría de la investigación científica. Buenos Aires: Eudeba; 1993.

5. Lefebvre H. Lógica formal/lógica dialética. Rio de Janeiro: Editora Civilização Brasileira; 1975.

6. Goldman L. Epistemologia e filosofia política. Lisboa: Editora Presença; 1984.

7. Denzin N, Lincoln Y, organizadores. O planejamento da pesquisa qualitativa. Teorias e abordagens. Porto Alegre: Editora Artmed; 2006.

8. Kuhn T. A estrutura das revoluções científicas. São Paulo: Editora Perspectiva; 1992.

\section{Colaboradores}

L. B. Schraiber concebeu e redigiu o artigo, respondendo por todas as pesquisas cujos dados são utilizados. A. F. P. L. d'Oliveira participou da redação final do artigo e responde pelas pesquisas com mulheres e redes de serviços. M. T. Couto participou da redação final do artigo e responde pelas pesquisas com homens e masculinidades.

\section{Agradecimentos}

As autoras agradecem ao professor José Ricardo Ayres pela cuidadosa leitura do original e contribuições.
9. Saffioti HIB, Almeida SS. Violência de gênero: poder e impotência. Rio de Janeiro: Editora Revinter; 1995.

10. Heise L, Ellsberg M, Gottemoeller M. Ending violence against women. Popul Rep 1999; 27:1-43.

11. Garcia-Moreno C, Jansen HA, Ellsberg M, Heise L, Watts CH; WHO Multi-country Study on Women's Health and Domestic Violence Against Women Study Team. Prevalence of intimate partner violence: findings from the WHO multi-country study on women's health and domestic violence. Lancet 2006; 368:1260-9.

12. Tjaden P, Thoennes N. Prevalence and consequences of male-to-female and female-to-male intimate partner violence as measured by the national violence against women survey. Violence Against Women 2000; 6:142-61.

13. Couto MT, Schraiber LB, d'Oliveira AFPL, Kiss LB. Concepções de gênero entre homens e mulheres de baixa renda e escolaridade acerca da violência contra a mulher, São Paulo, Brasil. Ciênc Saúde Coletiva 2006; 11 Suppl:1323-32. 
14. Schraiber LB, d'Oliveira AFPL, França Jr. I, Diniz S, Portella AP, Ludermir AB, et al. Prevalência da violência contra a mulher por parceiro íntimo em regiões do Brasil. Rev Saúde Pública 2007; 41:797-807.

15. Krug EG, Dahlberg LL, Mercy JA, Zwi AB, Lozano R. World report on violence and health. Geneva: World Health Organization; 2002.

16. Ardoino J. A complexidade. In: Morin E, organizador. A religação dos saberes. O desafio do século XXI. Rio de Janeiro: Editora Bertrand Brasil; 2001. p. $548-58$

17. Morin E. Os desafios da complexidade. In: Morin E, organizador. A religação dos saberes. O desafio do século XXI. Rio de Janeiro: Editora Bertrand Brasil; 2001. p. 559-67.

18. Habermas J. O discurso filosófico da modernidade. Lisboa: Publicações D. Quixote; 1990.

19. Ayres JRCM. Epidemiologia e emancipação. São Paulo: Editora Hucitec/Rio de Janeiro: ABRASCO; 1995.

20. Giffin KM. Produção do conhecimento em um mundo "problemático": contribuições de um feminismo dialético e relacional. Revista Estudos Feministas 2006; 14:635-54

21. Oliveira EM, Vilellla W. O campo da saúde coletiva à luz das relações de gênero: um diálogo difícil e conflituoso. In: Swain NT, Muniz GD, organizadores. Mulheres em ação: práticas discursivas, práticas políticas. Florianópolis: Editora das Mulheres; 2005. p. 101-20.

22. Barsted LL. O campo político-legislativo dos direitos sexuais e reprodutivos no Brasil. In: Berquó E, organizador. Sexo \& vida: panorama da saúde reprodutiva no Brasil. São Paulo: Editora Unicamp; 2003. p. 79-94.

23. Pitanguy J. Violência de gênero e saúde. Intersecções. In: Berquó E, organizador. Sexo \& vida: panorama da saúde reprodutiva no Brasil. São Paulo: Editora Unicamp; 2003. p. 319-37.

24. García JC. Juan César García entrevista Juan César García. In: Nunes ED, García JC, organizadores. As ciências sociais em saúde na América Latina: tendências e perspectivas. Brasília: Organização PanAmericana da Saúde; 1985. p. 21-8.

25. Minayo MCS, Souza ER. Violência e saúde como campo interdisciplinar e de ação coletiva. Hist Ciênc Saúde Manguinhos 1997; 4:513-31.

26. Araújo MF, Mattioli OC. Gênero e violência. São Paulo: Arte \& Ciência; 2004.

27. Machado Zanotta ML, Magalhães BTM. Violência conjugal: os espelhos e as marcas. In: Soárez M, Bandeira L, organizadores. Violência, gênero e crime no Distrito Federal. Brasília: Editora da UnB; 1999. p. 173-238.

28. Scott J. Gênero: uma categoria útil para a análise histórica. Educação e realidade 1995; 20:71-99.

29. Counts DA, Brown JK, Campbell JC, editores. Sanctions \& sanctuary. Cultural perspectives on beating of wives. Boulder: Westview Press; 1992.

30. Heise L. Violence against women: an integrated, ecological framework. Violence Against Women 1998; 4:262-90.
31. Schraiber LB, Couto MT. Homens, violência e saúde: uma contribuição para o campo de pesquisa e intervenção em gênero, violência doméstica e saúde. São Paulo: Faculdade de Medicina, Universidade de São Paulo; 2002.

32. Schraiber LB, d'Oliveira AFPL, França Jr. I, Diniz CSG, Portella AP, Ludermir AB, et al. The WHO multi country study on women's health and domestic violence against women - final report, Brazil. São Paulo: Faculdade de Medicina, Universidade de São Paulo; 2002.

33. World Health Organization. Putting women's safety first: ethical and safety recommendations for research on domestic violence against women. Geneva: World Health Organization; 1999.

34. Ellsberg MC, Heise L, Peña R, Agurto S, Winkvist A. Researching domestic violence against women: methodological and ethical considerations. Stud Fam Plann 2001; 32:3-15.

35. Habermas J. O conceito de poder deHannah Arendt. In: Freitag B, Rouanet SP, organizadores. Habermas. São Paulo: Editora Ática; 1993. p. 100-18 (Coleção Grandes Cientistas Sociais).

36. Freitag B, Rouanet SP. Introdução In: Freitag B, Rouanet SP, organizadores. Habermas. São Paulo: Editora Ática; 1993. p. 9-67. (Coleção Grandes Cientistas Sociais).

37. Arendt H. Sobre a violência. Rio de Janeiro: Editora Relume Dumará; 1994.

38. Costa JF. Violencia e psicanálise. Rio de Janeiro: Edições Graal; 1986.

39. Foucault M. O sujeito e o poder. In: Rabinow P Dreyfus HL. Michel Foucault. Uma trajetória filosófica (para além do estruturalismo e da hermenêutica). Rio de Janeiro: Editora Forense-Universitária; 1995. p. 231-49.

40. Bubber M. Eu e tu. São Paulo: Cortez e Moraes; 1977.

41. Lévinas E. Humanismo do outro homem. Petrópolis: Editora Vozes; 1993.

42. Ellsberg MCT, Herrera A, Winkvist A, Kullgren G. Domestic violence and emotional distress among nicaraguan women: results from a population based study. Am Psychol 1999; 54:30-6.

43. Schraiber LB, d'Oliveira AFPL, Hanada H, Figueiredo WS, Couto MT, Kiss LB, et al. Violencia vivida: a dor que não tem nome. Interface Comun Saúde Educ 2003; 7:41-54.

44. Schraiber LB, d'Oliveira AFPL, Falcão NTC, Figueiredo WS. Violência dói e não é direito: a violência contra a mulher, a saúde e os direitos humanos. São Paulo: Editora UNESP; 2005.

45. Schraiber LB, d'Oliveira AFPL, Couto MT, Hanada H, Kiss LB, Durand J, et al. Violência contra a mulher entre usuárias de serviços básicos de saúde da rede pública da grande São Paulo. Rev Saúde Pública 2007; 41:359-67.

46. Jansen HAFM, Watts C, Ellsberg M, Heise L, GarciaMoreno C. Interviewer training in the WHO Multicountry Study on Women's Health and Domestic Violence. Violence Against Women 2004; 10: 831-49.

Recebido em 08/Jan/2008

Versão final reapresentada em 03/Jun/2008

Aprovado em 16/Jun/2008 